UDK: 662.63:662.61

DOI: https://doi.org/10.24867/05AM07Vranjesevic

\title{
ISTRAŽIVANJE STRUJANJA KROZ CEV MEŠAVINE VODE I ETILEN GLIKOLA SA NANOČESTICAMA SREBRA
}

\section{RESEARCH OF THE FLOW OF WATER/ETHYLENE - GLYCOL MIXTURE WITH SILVER NANOPARTICLES TROUGH PIPE}

\author{
Nikola Vranješević, Fakultet tehničkih nauka, Novi Sad
}

\begin{abstract}
Oblast - MAŠINSTVO
Kratak sadržaj - Predmet ovog rada su hidrauličke karakteristike strujanja mešavine vode $i$ etilen glikola sa nanočesticama srebra kroz pravu cev. Cilj ovog rada je da se utvrde hidrauličke karakteristike strujanja razmatranog nanofluida kroz pravu cev pri laminarnom režimu $i$ stacionarnim uslovima strujanja. Istraživanje je urađeno primenom računarske dinamike fluida (computational fluid dynamics - CFD). Utvrđeno je da pad pritiska raste sa porastom Rejnoldsovog broja i koncentracijom nanočestica srebra razmatranog nanofluida.
\end{abstract}

Abstract - The subject of this paper is the hydraulics characteristics of the flow of water/ethylene - glycol mixture with silver nanoparicles trough the straight pipe. Purpose of this paper is to determine the hydraulics characteristics of the flow of the considered nanofluid through the straight pipe in the laminar regime and the steady flow conditions. The research was done by using the computational fluid dynamics - CFD. It was found that the pressure drop increased with the increase of the Reynolds number and the concentration of silver nanoparticles in the considered nanofluid.

Ključne reči: Računarska dinamika fluida, nanofluidi, pad pritiska, koeficijent trenja.

\section{UVOD}

$\mathrm{U}$ radu će biti ispitane hidrauličke karakteristike nanofluida primenom računarske dinamike fluida. Koristiće se komercijalni softverski program Star CCM+. Hidrauličke karakteristike razmatranog nanofluida bile su predmet eksperimentalnog istraživanja u prošlosti. U radu će se ponoviti sprovedeno eksperimentalno istraživanje predmetnog nanofluida samo sada primenom računarske dinamike fluida. Koristiće se identična geometrija fizičkog modela u softveru bez aproksimacija. Numeričke simulacije podesiće se na osnovu fizičkih svojstava dobijenih predhodnim eksperimentalnim istraživanjem. Zid cevi će se posmatrati kao adijabatna površina, što je odstupanje od fizičkog modela. Kod fizičkog modela toplota je odvođena preko spoljašnje površine cevi. Numeričke simulacije će se izvesti za šest različitih zapreminskih koncentracija nanočestica u osnovnom fluidu $(0 \%, 0,05 \%, 0,1 \%, 0,15 \%, 0,3 \%$ i $0,45 \%)$.

\section{NAPOMENA:}

Ovaj rad proistekao je iz master rada čiji mentor je bio prof. dr Siniša Bikić.
Temperatura nanofluida na ulazu u cev biće $10{ }^{\circ} \mathrm{C}$. Za svaki navedeni slučaj, maseni protok nanofluida će se varirati od $5 \mathrm{~g} / \mathrm{s}$ do $30 \mathrm{~g} / \mathrm{s}$. Na ovaj način će se numeričke simulacije predmetnog fluida uraditi za laminaran režim i stacionarne uslove strujanja. Verifikacija podataka numeričke simulacije uradiće sa vodom primenom Darsi - Vajbahovog (Darcy - Weibach) modela.

\section{OPIS EKSPERIMENTALNOG POSTROJENJA}

Na slici 3.1 prikazano je eksperimentalno postrojenje za ispitivanje nanofluida korišćeno $u$ predhodnom istraživanju [1]. Eksperimentalno ispitivanje hidrauličkih karakteristika urađeno je na suprotnosmernom razmenjivaču toplote tipa cev u cevi. Dužina unutrašnje cevi razmenjivača iznosi $2,97 \mathrm{~m}$. Unutrašnji prečnici unutrašnje i spoljašnje cevi su 4,3 mm i 10,5 mm.

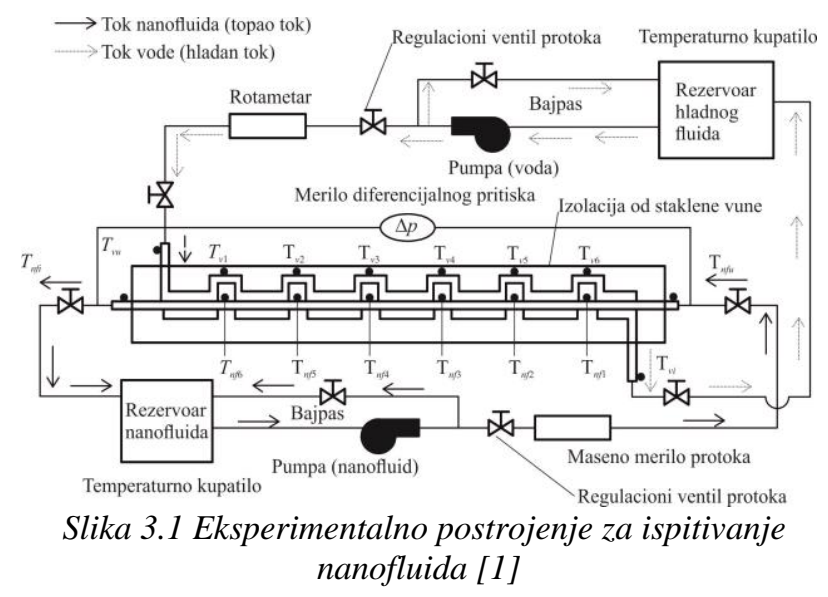

Numeričke simulacije urađene su za dva slučaja. U prvom slučaju (slučaj I) nanočestice srebra pomešane su sa surfaktantom u razmeri 50:50. Surfaktant je sodijum dodecil sulfat (SDS).

Za ovaj slučaj prethodnim eksperimentalnim istraživanjem su određene jednačine zavisnosti viskoznosti i gustine fluida od temperature i koncentracije čvrstih čestica. U drugom slučaju (slučaj II) nanočestice koje su dodate u osnovni fluid su čisto srebro. Takođe, za određivanje viskoznosti i gustine ovakvog fluida korišćeni su teorijski modeli za fluid sa čvrstim česticama. 


\section{TEORIJSKE OSNOVE}

Prilikom eksperimentalnog merenja viskoznosti Ag/EG$\mathrm{H}_{2} \mathrm{O}$ nanofluida korišćen je Cannon-Fenske prozirni kapilarni viskozimetar. Kapilarnim viskozimetrom merena je kinematska viskoznost nanofluida. $\mathrm{Na}$ osnovu dobijene vrednosti kinematske viskoznosti određena je dinamička viskoznost nanofluida iz poznate relacije:

$$
\mu=\rho \cdot v,
$$

gde je $\rho$ - gustina fluida $\left[\mathrm{kg} / \mathrm{m}^{3}\right]$.

Dobijene vrednosti viskoznosti upoređene su sa postojećim modelom za određivanje kinematske viskoznosti. Postojeći model sa kojima je rezultat upoređen je Anštajnov (Einstein) model:

$$
\frac{\mu_{n f}}{\mu_{o f}}=(1-\phi)^{-2,5},
$$

gde su:

$$
\begin{aligned}
& \mu_{n f}-\text { dinamička viskoznosti nanofluida }[\mathrm{Pa} \cdot \mathrm{s}] \text {; } \\
& \mu_{o f}-\text { dinamička viskoznosti osnovnog } \\
& \text { fluida }[\mathrm{Pa} \cdot \mathrm{s}] ; \\
& \phi-\text { zapreminski udeo nanočestica }[-] .
\end{aligned}
$$

Upoređivanjem rezultata eksperimenta i teorijskog modela predložena je jednačina koja uzima u obzir $\mathrm{i}$ temperaturu i zapreminski udeo nanočestica [1]:

$$
\frac{\mu_{n f}}{\mu_{o f}}=1,0511-0,9641 \phi+0,439 \phi T-0,0004 T,
$$

gde su:

$$
\begin{aligned}
& \mu_{n f}-\text { dinamička viskoznosti nanofluida }[\mathrm{Pa} \cdot \mathrm{s}] ; \\
& \mu_{o f}-\text { dinamička viskoznost osnovnog } \\
& \quad \text { fluida }[\mathrm{Pa} \cdot \mathrm{s}] ; \\
& \phi-\text { zapreminski udeo nanočestica }[-] \mathrm{i} \\
& T \text { - temperatura nanofluida }[\mathrm{K}] .
\end{aligned}
$$

Merenje gustine $\mathrm{Ag} / \mathrm{EG}-\mathrm{H}_{2} \mathrm{O}$ nanofluida je urađeno pomoću elektronske vage i menzure zapremine $20 \mathrm{~mL}$. Gustina nanofluida određena je pomoću sledeće jednačine:

$$
\rho_{n f}=\frac{m_{t}-m_{p r m}}{V_{n f}}
$$

gde su:

$$
\begin{aligned}
& m_{t}-\text { ukupna masa nanofluida i menzure }[\mathrm{kg}] \\
& m_{p r m}-\text { masa prazne menzure }[\mathrm{kg}] \mathrm{i} \\
& V_{n f}-\text { zapremina nanofluida }\left[\mathrm{m}^{3}\right] .
\end{aligned}
$$

Izmerena gustina nanofluida upoređena je sa postojećim modelom Paka i Čoa (Pak and Cho):

$$
\rho_{n f}=(1-\phi) \rho_{o f}+\phi \cdot \rho_{p}
$$

gde su:

$$
\begin{aligned}
& \rho_{\text {of }}-\text { gustina osnovnog fluida }\left[\mathrm{kg} / \mathrm{m}^{3}\right] \\
& \rho_{p}-\text { gustina materijala nanočestice }\left[\mathrm{kg} / \mathrm{m}^{3}\right] \mathrm{i} \\
& \phi-\text { zapreminski udeo nanočestica }[-] .
\end{aligned}
$$

Upoređivanjem eksperimentalnih podataka sa postojećim modelom dobijena je jednačina za određivanje gustine nanofluida koja uzima u obzir i temperaturu i zapreminski udeo nanočestica:

$$
\frac{\rho_{n f}}{\rho_{o f}}=1+0,041 \phi+0,0012 \phi T+4,276 \times 10^{-5} T,
$$

gde je $T$ - temperatura nanofluida $[\mathrm{K}]$.

Tokom eksperimenta podešavan je maseni protok. Poznavanjem masenog protoka iz izraza za određivanje masenog protoka određena je brzina strujanja:

$$
v=\frac{4 \cdot \dot{m}}{D^{2} \cdot \pi \cdot \rho},
$$

gde su:

$$
\begin{aligned}
& \dot{m} \text { - maseni protok }[\mathrm{kg} / \mathrm{s}] \\
& v-\text { brzina fluida }[\mathrm{m} / \mathrm{s}] ; \\
& \rho-\text { gustina fluida }\left[\mathrm{kg} / \mathrm{m}^{3}\right] \mathrm{i} \\
& D-\text { unutrašnji prečnik cevi }[\mathrm{m}] .
\end{aligned}
$$

Poznavanjem prethodno navedenih veličina određen je Rejnoldsov broj iz dobro poznate relacije:

$$
R e=\frac{v \cdot D}{v},
$$

gde su:

$$
\begin{aligned}
& R e-\text { Rejnoldsov broj [-] i } \\
& v \text { - kinematska viskoznost fluida }\left[\mathrm{m}^{2} / \mathrm{s}\right] .
\end{aligned}
$$

Eksperiment je izveden za laminarno strujanje fluida. Koeficijent trenja za laminaran režim strujanja određen je iz sledeće relacije:

$$
\lambda=\frac{64}{R e},
$$

gde je $\lambda$ - koeficijent trenja [-].

Pad pritiska na ravnoj, pravoj deonici definisan je Darsi Vajbahovim (Darcy - Weibach) modelom:

$$
\Delta p=\rho \cdot \lambda \cdot \frac{L}{D} \cdot \frac{v^{2}}{2},
$$

gde su:

$$
\begin{aligned}
& \Delta p \text { - pad pritiska }[\mathrm{Pa}] \mathrm{i} \\
& L-\text { dužina cevi }[\mathrm{m}] .
\end{aligned}
$$

\section{REZULTATI I DISKUSIJA}

Iz literature [2] su preuzete vrednosti za gustinu i viskoznost vode i pomoću Darsi - Vajbahovog (Darcy Weibach) modela izračunat je pad pritiska za geometriju modela. Dobijeni rezultati su upoređeni sa odgovarajućim rezultatima dobijenim numeričkim simulacijama. U tabeli 1 prikazani su rezultati verifikacije numeričke simulacije vodom primenom Darci Vajbahovog modela.

Tabela 1 Rezultati verifikacije numeričke simulacije

\begin{tabular}{|l|c|c|c|c|c|c|}
\hline$T\left({ }^{\circ} \mathrm{C}\right)$ & \multicolumn{2}{|c|}{2} & \multicolumn{2}{c|}{5} & \multicolumn{2}{c|}{10} \\
\hline$\dot{m}(\mathrm{~g} / \mathrm{s})$ & 5 & 10 & 5 & 10 & 5 & 10 \\
\hline$R \mathrm{e}(-)$ & 875 & 1750 & 957 & 1914 & 1133 & 2267 \\
\hline$\Delta p_{\text {teo. }}(\mathrm{Pa})$ & 2994 & 5988 & 2737 & 5475 & 2312 & 4623 \\
\hline$\Delta p_{\text {izm. }}(\mathrm{Pa})$ & 3072 & 6295 & 2816 & 5781 & 2390 & 4929 \\
\hline$\varepsilon(\%)$ & 2,6 & 5,1 & 2,8 & 5,6 & 3,4 & 6,6 \\
\hline
\end{tabular}

Zavisnost pada pritiska od Rejnoldsovog broja i koncentracije nanočestica za temperaturu od $10{ }^{\circ} \mathrm{C}$ dobijena eksperimentalnim putem prikazana je na slici 2 . 
Zavisnost pada pritiska od Rejnoldsovog broja i koncentracije nanočestica za temperaturu od $10{ }^{\circ} \mathrm{C}$ dobijena računarskom dinamikom fluida za slučaj I prikazana je na slici 3 . U oba slučaja pad pritiska ima trend rasta sa povećanjem Rejnoldsovog broja i sa povećanjem koncentracije nanočestica u nanofluidu. Kako se koncentracija nanočestica povećava od 0 vol\% do 0,15 vol\%, povećanje pada pritiska je malo. Iznad 0,15 vol\% povećanje pada pritiska je znatno više.

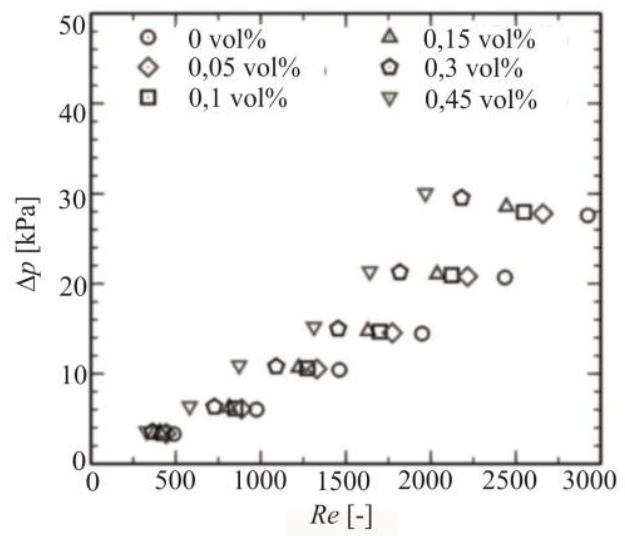

Slika 2 Zavisnost pada pritiska od Rejnoldsovog broja $i$ koncentracije nanočestica dobijena eksperimentom [1]

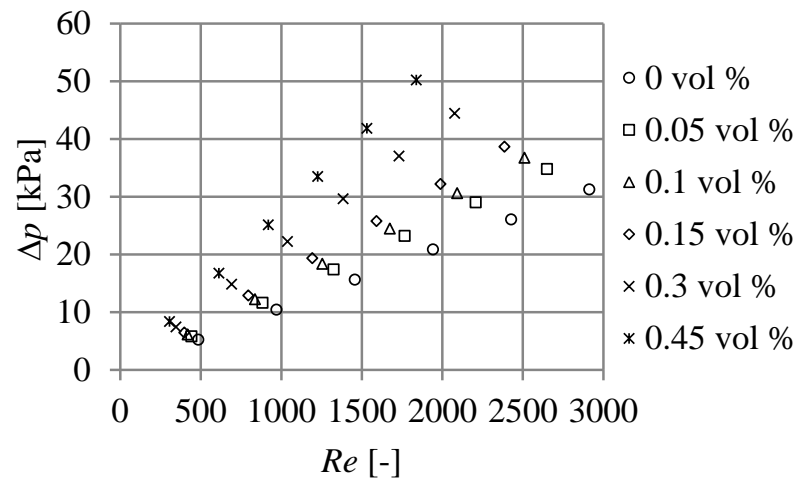

Slika 3 Zavisnost pada pritiska od Rejnoldsovog broja $i$ koncentracije nanočestica dobijena računarskom dinamikom fluida - slučaj I

Slika 4 prikazuje rezultate simulacije za slučaj II sa $100 \%$ čistim srebrom kao nanočesticama. Na slici se vidi da se vrednost pada pritiska menja isključivo sa Rejnoldsovim brojem.

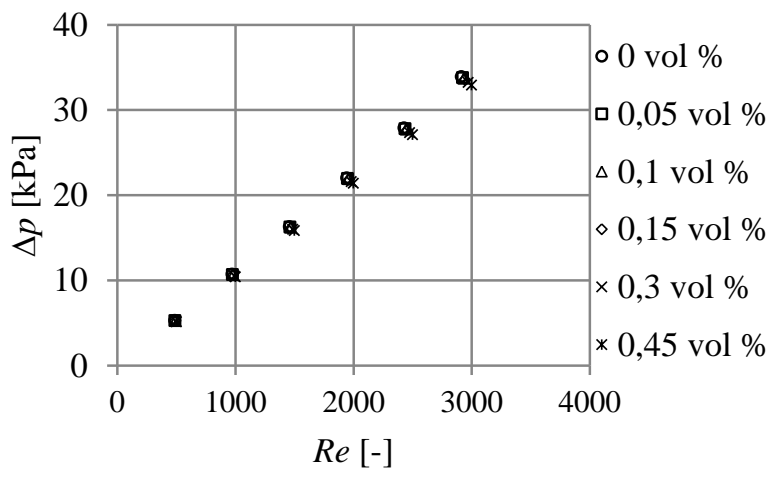

Slika 4 Zavisnost pada pritiska od Rejnoldsovog broja $i$ koncentracije nanočestica dobijena računarskom dinamikom fluida - slučaj II
Razlog za tako nešto leži u matematičkom modelu za računanje viskoznosti. (2) koji je ovde upotrebljen, a koji ne uzima $\mathrm{u}$ obzor uticaj temperature na viskoznost nanofluida. Time se dobijaju jako bliske vrednosti za koeficijent viskoznosti za bilo koju koncentraciju nanočestica, pa se samim tim i rezultati za pad pritiska za različite koncentracije nanočestica poklapaju. Kako bi se postojeći teorijski model mogao upotrebiti u oblasti nanofluida potrebna je njegova korekcija. Na slici 5 prikazana je zavisnost koeficijenta trenja od Rejnoldsovog broja i koncentracije nanočestica na temperaturi $10^{\circ} \mathrm{C}$ dobijena eksperimentalnim putem. Može da se vidi da koeficijent trenja znatno menja sa porastom Rejnoldsovog broja, ali da je skoro konstantan ako se posmatra u odnosu na zapreminsku koncentraciju nanočestica. Pri nižim Rejnoldsovim brojevima primećuje se uticaj na koeficijent trenja sa promenom zapreminske koncentracije nanočestica. Pri višim Rejnoldsovim brojevima povećanje koeficijenta trenja sa promenom koncentracije nanočestica je veoma malo.

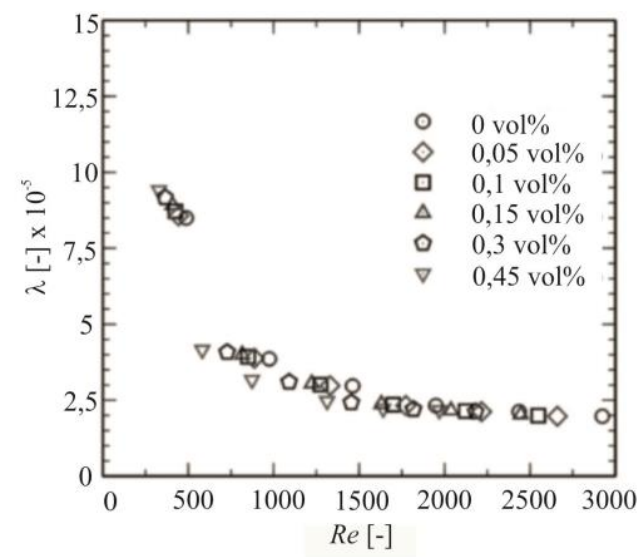

Slika 5 Zavisnost koeficijenta trenja od Rejnoldsovog broja i koncentracije nanočestica na temperaturi $10^{\circ} \mathrm{C}$ dobijena eksperimentalnim putem [1]

$\mathrm{Na}$ slici 6 prikazana je zavisnost koeficijenta trenja od Rejnoldsovog broja i koncentracije nanočestica na temperaturi $10^{\circ} \mathrm{C}$, dobijena primenom računarske dinamike fluida za slučaj I.

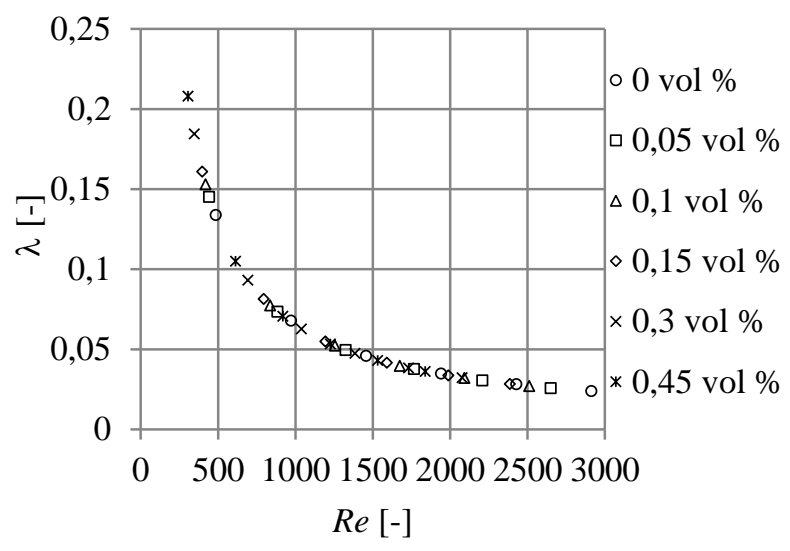

Slika 6 Zavisnost koeficijenta trenja od Rejnoldsovog broja i koncentracije nanočestica na temperaturi $10^{\circ} \mathrm{C}$ dobijena računarskom dinamikom fluida - slučaj I 
Na slici se vidi da se vrednost koeficijenta trenja znatno menja sa promenom Rejnoldsovog broja. Kod nižih Rejnoldovih brojeva promena koeficijenta trenja usled promene zapreminske koncentracije nanočestica je znatno izraženija.

Rezultatima numeričke simulacije dobijeni su isti trendovi kao i kod eksperimentalnih podataka. Vrednosti koeficijenta trenja dobijene primenom računarske dinamike fluida i eksperimentalnim putem se u dobroj meri poklapaju. Za slučaj II, slika 7, vidi se očigledna zavisnost koeficijenta trenja od Rejnoldsovog broja. Kao i u slučaju pada pritiska, u odnosu na zapreminsku koncentraciju nanočestica vrednost koeficijenta trenja gotovo da se ne menja. Razlog su vrednosti viskoznosti koje se dobijaju iz Ajnštajnove jednačine (2).

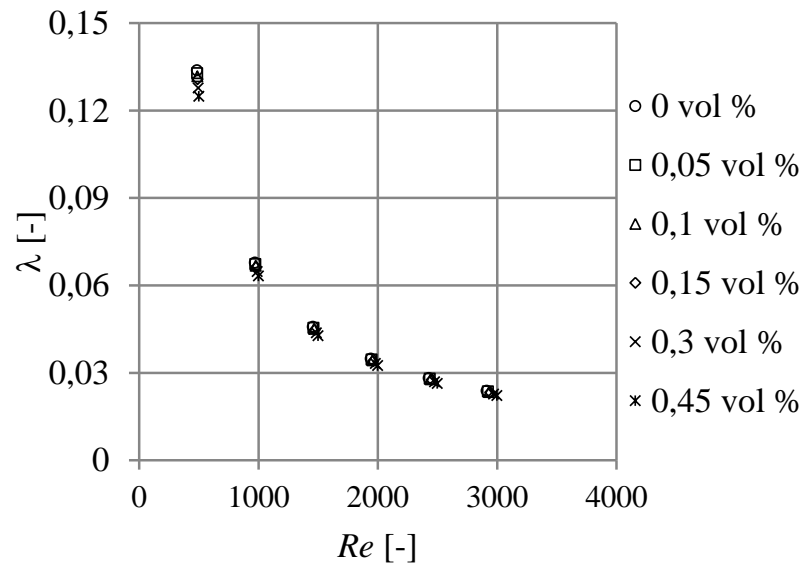

Slika 7 Zavisnost koeficijenta trenja od Rejnoldsovog broja i koncentracije nanočestica na temperaturi $10^{\circ} \mathrm{C}$ dobijena računarskom dinamikom fluida - slučaj II

\section{ZAKLJUČAK}

Utvrđeno je da hidrauličke karakteristike nanofluida koji je ispitan u ovom radu odgovaraju realnom ponašanju fluida i poklapaju se sa rezultatima eksperimenta. Porast pada pritiska uslovljen je povećanjem Rejnoldsovog. Uticaj nanočestica na pad pritiska je takođe značajan, jer nanočestice povećavaju viskoznost fluida.
Rejnoldsov broj ima značajan uticaj na koeficijent trenja, dok je uticaj koncentracije nanočestica na koeficijent trenja zanemarljiv. Povećanjem Rejnoldsovog broja preko 1000 ulazi se u zonu kada koeficijent trenja teži da bude konstantan.

Predložene jednačine za određivanje gustine i viskoznosti dobijene eksperimentalnim putem za nanofluid sa nanočesticama srebra su na ovaj način potvrđene primenom računarske dinamike fluida. Takođe je potvrđeno da je teorijski model za određivanje viskoznosti fluida sa dodatim česticama nepouzdan za razmatrani nanofluid jer ne obuhvata sve faktore koji imaju uticaj na ponašanje fluida.

\section{REFERENCE}

[1] C. Selvam, D. Mohan Lal and Sivasankaran Harish, Convective heat transfer behaviour of water-ethylene glycol-mixture with silver nanoparticles under laminar flow conditions, Journal of Mechanical Science and Technology 32 (5) (2018) 2191 2199.

[2] J. V. Sengers, J. T. R. Watson: Improved international formulations for the viscosity and thermal conductivity of water substance, J. Phys.Chem.Ref. Data, 15:1291, (1986).

Kratka biografija:

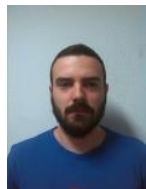

Nikola Vranješević, rođen je u Vršcu 1994 god. Master rad na Fakultetu tehničkih nauka iz oblasti Mašinstva - Naftna i gasna tehnika odbranio je 2019. god. 